\title{
ERRATUM
}

H. R. Sadraie • S. L. Crouch

\section{A spectral alternating method for elastostatic problems with multiple spherical cavities}

Published online: 20 September 2005

(C) Springer-Verlag 2005

Unfortunately, a few errors were printed in the original version. In the second expression on the second line below Eq. 3 and again, at the beginning of Eq. 5, $\psi$ should have been a capital in italics. $(\Psi)$
At the end of the paragraph under Eq. 17, the ij should be over the $\mathbf{t}$ and should not be a superscript. The legend to Fig. 7 was incorrect and the publisher apologizes for this error. The correct legend is shown here.

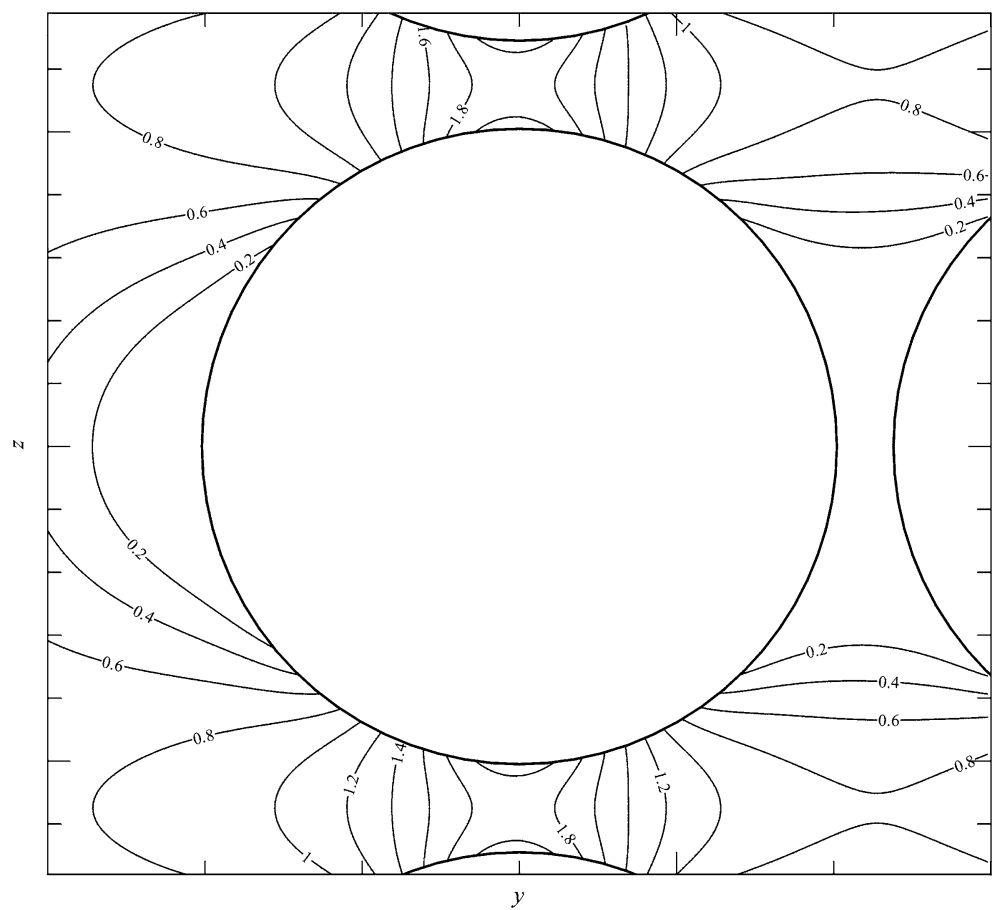

Fig. 7. A contour of $\sigma_{y y} / \sigma_{y y}^{(0)}$ in the y-z plane around the 11th cavity

The online version of the original article can be found at http://dx.doi.org/10.1007/s00466-005-0698-x

H. R. Sadraie $(\varangle) \cdot$ S. L. Crouch

Department of Civil Engineering University of Minnesota Minneapolis, MN 55455, USA

E-mail: sadra002@umn.edu 